\title{
AGING POPULATION IN CHANGE - A CRUCIAL CHALLENGE FOR STRUCTURALLY WEAK RURAL AREAS IN AUSTRIA
}

\author{
Tatjana Fischer ${ }^{1}$
}

Received 15 November 2012; Accepted 12 April 2013

\begin{abstract}
Besides population decline, structurally weak rural areas in Austria face a new challenge related to demographic change: the increasing heterogeneity of their aging population. From the example of the so-called 'best agers' - comprising people aged 55 to 65 years - this contribution makes visible patterns and consequences of growing individualized spatial behaviour and spatial perception. Furthermore, contradictions between claims, wishes and expectations and actual engagement and commitment to their residential rural municipalities are being pointed out. These empirically-based facts are rounded off by considerations on the best agers' future migration-behaviour and the challenges for spatial planning at the municipal level.
\end{abstract}

Key words: rural aging in change, spatial planning, challenges

Kurzfassung: Neben der Schrumpfung der Bevölkerung müssen sich ländliche Räume in Österreich einer weiteren Herausforderung des demographischen Wandels stellen: der Heterogenisierung der älteren Landbevölkerung hinsichtlich deren Ansprüche und Wünsche an ihre Wohnumgebung. Dieser Beitrag zeigt am Beispiel der sog. best ager, d. h. Personen im Alter von 55 bis 65 Jahren, und belegt durch aktuelles empirisches Datenmaterial deren zunehmende Individualisierung in Hinblick auf Raumverhalten, Raumwahrnehmung und Beitrag zur sozialen Kohäsion sowie zur Gemeindeentwicklung auf. Inhaltlich abgerundet wird der Artikel von Überlegungen zum zukünftigen Abwanderungs- und Bleibeverhalten der heute jungen Seniorlnnen und den daraus resultierenden Herausforderungen für die Raumplanung auf kommunaler Ebene.

Schlagwörter: ältere Landbevölkerung im Wandel, Herausforderungen für die Raumplanung

\section{Introduction}

Demographic change is a slow process that causes structural shifts of the age structure of a population. These quantitative shifts often lead to aging and population decline in structurally weak areas in the long run. Besides this, qualitative - still invisible - changes within the older generation of high relevance for spatial planning in rural areas take place: heterogeneity and singularization. In all situations where small population and heterogeneity of primary dwellers

\footnotetext{
${ }^{1}$ Mag. Dr. Tatjana Fischer, Institute for Spatial Planning and Rural Development, University of Natural Resources and Life Sciences Vienna; Peter-Jordan-Straße 82, 1190 Wien, phone 43147654 5368; e-mail: tatjana.fischer@boku.ac.at
} 
overlap, it becomes unsure, how sustainable municipal or rather regional planning - seen as securing quality of life for all population groups - could be carried out.

In this context, it has to be stressed that spatial planning is a cross-sectional public task that must not only focus on favoured sub-groups within the population of a defined territory. Its main task is to offer preventive and solution-oriented approaches to maintain quality of life for all stakeholders within the population based on the paradigms of equivalence and equal opportunities in the area of conflict between spatial organisation and spatial development.

From a spatial point of view, (future) challenges structurally weak rural municipalities have to face (e. g. the stabilisation of the amount of primary dwellers among the older generation, matching various needs and desires of an aging population in change against the background of declining financial opportunities), (may) result from specifics of spatial behaviour, spatial perception, social inclusion and political participation.

Furthermore, the (future) migration behaviour at old age is of high interest, because information on willingness to age in place and the amount of the (future) demanders is necessary to consider solutions for provision of infrastructure and alternative supply-side structures of goods and services at the municipal level.

Research within the field of spatial planning must not end with analysis of the findings, but has to provide solutions for political decision makers at different spatial levels. Related to this claim, recommendations found in literature often focus on an abstract level (see Born, Goltz and Saupe 2004).

Walsh et al. (2012) point out that "due to the small-scale nature of the research, and the diverse contextual factors of place and the heterogeneity of the rural older population, it is not possible to generalise our findings to other rural settings" (p. 9).

In an international context, findings from Austrian researchers on intermediate spatial research on rural aging and rural aging in transition - comprising sociological, gerontological and spatial aspects - are rare, because among other things in Austria spatial research on rural aging has no long-standing tradition (Fischer 2005).

\section{Approaching the topic of "rural aging" and discovering key issues}

Much research on "aging in rural areas" in its widest sense has already been conducted. Burholt and Dobbs (2012) provide comprising and revealing of the state of play of research on rural aging in Europe at the interface of space, gerontology and sociology. During the last decade, alongside theoretical works numerous empirically-based case-studies at different spatial scales and sample sizes deal among other issues with the quantitative dimensions of demographic changes (shifts within the population structure) on the one hand, and impacts of these changes on health issues, access to services, social relationships and participation on the other hand. Furthermore, urban-rural-migration of senior citizens and loyalty to rural location of autochthon older population and older in-migrants, as well as on technological aspects in order to maintain quality of life of an aging rural population are of interest of various studies.

In this paper the author presents preliminary results of her current research project on rural primary dwellers aged 55 to 65 years in six selected structurally weak rural municipalities in Austria dealing with the question on how the older rural population has changed over time regarding their spatially-related traits and attitudes due to the individualisation of occupational and migration biographies and availabilities of resources like money, time, health state, and social networks.

2012 was the European Year of Active Aging and Solidarity of Generations. Thus, it is a good hook to start thinking about, whether and how changes of the rural older population cause impacts on municipal spatial planning and adequate solutions for an assumed increasing heterogeneous population group. These challenges are being operationalized and made visible by the consequences of individualized demander profiles relating to the supply of goods and services, the comparison of claims, wishes and expectations to actual engagement and 
commitment to their residential rural municipalities; as well as the motives for their future migration-behaviour of today's best-agers aged 55 to 65 years.

Qualitative information taken from other research of the author (Fischer 2005, Fischer 2009) on the interrelations of spatial aspects and quality of life at old age help better to understand not only the "complex population transition", but also the "implications of this demographic shift" (Davies 2011, 191) and to figure out the (potential future) challenges for structurally weak rural municipalities related to evidence based policy that arise from the changes among the population group of the best agers overlaid by economic and structural changes in rural areas, in general.

The empirical basis of this article comprises primary data collected by the author in 2012 . A written survey has been conducted among the basic population of the primary and secondary dwellers aged 55 to 65 years in six selected structurally weak small rural municipalities of three provinces (Burgenland, Lower Austria, Styria) of Austria.

Thanks to the support of the mayors, the author got the names and addresses of all persons born 1947 to 1957 presently having their principal residences or rather second homes there.

The standardized written survey was conducted among 941 persons. A pre-addressed and paid reply envelope was added in order to raise the response rate.

The questionnaire comprised 59 questions, among them 27 open questions, 11 semi-open questions, and 21 closed-ended questions. Among the latter, 9 questions offered the opportunity of multiple choice.

\begin{tabular}{|l|r|r|r|r|r|}
\hline Municipality & \multicolumn{5}{|c|}{ Response Rate (in \%) } \\
\hline & In total & female & male & \multicolumn{1}{|c|}{$\begin{array}{l}\text { primary } \\
\text { dwellers }\end{array}$} & $\begin{array}{r}\text { second } \\
\text { home } \\
\text { owners }\end{array}$ \\
\hline $\begin{array}{l}\text { Bernhardstha } \\
\text { I }\end{array}$ & $58(31.4 \%)$ & $25(29.0 \%)$ & $33(33.3 \%)$ & $47(31.8 \%)$ & $11(29.7 \%)$ \\
\hline Rabensburg & $60(23.5 \%)$ & $35(26.1 \%)$ & $25(20.7 \%)$ & $54(25.5 \%)$ & $6(13.9 \%)$ \\
\hline Kapellen & $21(20.0 \%)$ & $5(9.3 \%)$ & $16(31.4 \%)$ & $21(22.8 \%)$ & $0(0.0 \%)$ \\
\hline Mürzsteg & $20(18.5 \%)$ & $11(20.4 \%)$ & $9(16.7 \%)$ & $13(20.3 \%)$ & $7(15.9 \%)$ \\
\hline Eberau & $59(27.3 \%)$ & $31(29.8 \%)$ & $28(25.0 \%)$ & $45(26.0 \%)$ & $14(32.6 \%)$ \\
\hline Rohr im Bgld. & $24(33.3 \%)$ & $11(31.4 \%)$ & $13(35.1 \%)$ & $24(35.3 \%)$ & $0(0.0 \%)$ \\
\hline in total & $242(25.7 \%)$ & $118(25.3 \%)$ & $124(26.2 \%)$ & $204(26.9 \%)$ & $38(20.7 \%)$ \\
\hline
\end{tabular}

Tab 1. Population and response rate.

\begin{tabular}{|l|r|r|r|}
\hline Selected characteristics of respondents & \multicolumn{1}{|c|}{ women } & \multicolumn{1}{c|}{ in total } \\
\hline respondents among the primary dwellers & 97 & 107 & 204 \\
\hline marital status: married / living in partnership & $76 / 1$ & $92 / 3$ & $168 / 4$ \\
\hline born/grown up in today's residential municipality & 42 & 38 & 80 \\
\hline still employed & 23 & 38 & 61 \\
\hline living in one- or two family houses & 89 & 101 & 190 \\
\hline
\end{tabular}

Tab 2. Socio-demographic profile of the respondents.

Note: The following presented results only refer to the primary dwellers. Differences among the case-study municipalities regarding the attributes and traits of the best agers are not being pointed out.

\section{Empirical evidence}

\section{Characteristics and traits of today's best agers}

According to the information given by the best agers themselves, other findings from the author (Fischer 2005), and international research findings (amongst many others see Geißler 2003; Glasgow and Brown 2012; Born, Goltz and Saupe 2004), they differ to their parents as follows: comfortable or rather sufficient income, no physically demanding work, still being in good health 
(and "still alive"), active, more spare-time available, differentiated leisure activities, and travel activities.

Furthermore, there is a big variety related to occupational and migration biographies: about $40 \%$ of the (former) working people have been or rather partly still are commuters; more than threefourths always have been primary dwellers in their present residence community, and about $20 \%$ of the respondents have moved to their present residence community within the last ten years. In contrast, only $5 \%$ belong to the farming community.

A common similarity referring to the housing situation of the rural best agers can be detected: more than $90 \%$ are living in one- or rather two-family-houses.

Notable differences regarding the availability and assistance for or from family members have been identified: e. g. in about $20 \%$ of cases the respondents and their (adult) children live within the same municipality.

\section{Particularities of the best agers' spatial behaviour: high external orientation referred to their shopping behaviour and high loyalty to location referred to their leisure behaviour}

The organisation and structuring of the best agers daily life is built on auto-mobility. About $90 \%$ of the respondents are car drivers. Their trip chains are quite complex and characterized by high external orientation regarding shopping and leisure activities. Carpooling is quite rare.

More than $90 \%$ of all respondents agree to the quotation "I have to leave (my residential municipality) for daily provision". In contrast, about $50 \%$ of them rate the quality of the local offering structures of daily supply "very good" (14 persons), "good" ( 53 persons) and "sufficient" (45 persons). About $60 \%$ of those who rate the provision quality "very good", "good" or "sufficient" buy locally, too. Additionally, $40 \%$ of the non-automobile best agers organise their provision with goods of daily demand elsewhere.

This mismatch of individual evaluation and actual spatial action matterns allows for conclusions to subjective definitions and adequacy related to the quality of supply structures, and gives notice to substitutes - Erickson, Call and Brown (2012) call it mitigation - to flee local infrastructural deficiencies.

\section{Spatial Perception: unpleasant changes and deficiencies are being balanced individually with amenities and emotional bonds}

The main reasons in order to feel good in the place where the respondents live comprise "one's own house and garden", "subjective well-being", "private reasons", "one's origin", as well as "relations to the (former) workplace and proximity to infrastructure". This reflects the emotional loyalty to the present residential municipality: For the best agers "house and garden" is the most binding factor, followed by "one's marital partner", "one's origin ("grown up here"), and "my friends are living here".

Furthermore, the best agers highly appreciate landscape connected amenities of the immediate residential environment (see also Born, Goltz and Saupe 2004), followed by "security". Other factors that contribute to individual well-being are the qualities of the associative life and the "village community.

All amenities mentioned earlier as well as the relevance of one's own house and garden significantly influence the leisure behaviour of the respondents: about $50 \%$ prefer spending their "spare time" at home (works around the house and the garden, pursuing one's hobbies), which expresses high loyalty to location (see also Walsh et al. 2012).

Asked for the most annoying aspects, one fourth does not respond. About $20 \%$ are quite satisfied with the quality of life in their present residential municipality. Many respondents complain about municipal policy and the bad financial situation of the municipality, the lack of cooperation between the political parties at the municipal level and few opportunities for civic participation. $10 \%$ claim about the lack of infrastructure (e.g. to few inns or meeting points for senior citizens), as well as the insufficient situation relating to public transport. Furthermore, one 
of ten feels uncomfortable about increasing egoism, intrigues, chit chat, small-mindedness, bigotry, and the loss of "old values".

Deficiencies expressed by the best agers widely cover the annoying aspects and are concentrated on the decrease of social cohesion, as well as the loss and lack of infrastructure. Due to high auto mobility rate only $2 \%$ of the respondents complain about long distances to (regional) centres and car dependency.

In the view of a small number of respondents infrastructural deficiencies over time really have turned into burdens and already have lead to losses of one's subjective quality of life.

Most of the respondents always have been primary dwellers in their present residential municipalities. Maybe that is why they are aware of structural and socio-spatial changes in their structurally weak rural municipalities carefully and monitor them precisely:

Over time, the respondents particularly observed changes concerning the appearance of the village. Furthermore, the loss of infrastructure (offering supply of goods), the aging of the population, the decline of social cohesion, and changes of the "social atmosphere" in the municipality have become evident. Nevertheless, about $80 \%$ of the respondents rate the quality of the village community "very good" to "satisfied.

Following van Dam, Heins and Elbersen (2002), the different layers of the rural - morphological aspects addressing to the "visual characteristics of the countryside", functional aspects "related to the spatial functions of the countryside" like "nature" or "recreation", as well as socio-cultural aspects related to "norms and values" of the countryside like peace or tranquillity and "topographical/locational aspects" (p. 465) - "mitigate" infrastructural deficiencies.

\section{Evaluating social inclusion: detecting the mismatch between self-described activity and actual engagement}

Social inclusion here is being operationalized by the indicators "volunteering" and "membership of political associations of older people". Volunteering again comprises "actual engagement in local associations", "neighbourhood assistance" and "other forms of mutual assistance".

Despite the fact that two-thirds of the best agers describe themselves as "active", only $30 \%$ of them actually are engaged in local associations, $50 \%$ definitely are not. This is not completely consistent with the statement of the respondents related to the importance of the "associative life" as an amenity in their residential municipalities. This may relate to 'hidden', within the written survey occasionally only in specific cases addressed conflicts between long-term primary dwellers and in-migrants (see also Born, Goltz and Saupe 2004).

In everyday life neighbourhood assistance is an essential column of support for one third of the respondents. Besides, there exist other forms of mutual assistance, for instance support between family members or between friends. A small number of nine persons are being involved into activities related to care for the elderly or leadership of self-help groups.

Neither political associations of older people nor the church do not play an important role in the context of social cohesion of the best agers.

\section{Worries, wishes, articulation, and political participation}

Knowing about the best agers' thoughts concerning their worries and wishes related to later life help better to understand the above mentioned deficiencies and reasonableness in their rural residential municipalities. As a consequence, mainly unfulfilled wishes related to infrastructure from the financial point of view might be a driver for out-migration of small structurally weak rural municipalities. That implies the necessity to look at the worries having been expressed by the stakeholders precisely.

The identified worries can be categorised as the following: on the one hand, worries related to deceases, frailty, and dependency at old age and uncertainties related to financial developments and socio-economic status at old age, on the other hand spatially related worries. 
Among the latter "group" it is the loss of one's own auto mobility (see also Walsh et al. 2012), as well as the lack of barrier-freedom of one's own house and garden that are most relevant. In addition, one-tenth of the respondents ask for more social cohesion; $14 \%$ of the respondents (still) feel comfortable and do not perceive any deficiencies.

On the contrary, one third of the respondents state, that they do not think about the future yet.

A small number of those, who express their wishes, relate them to the demands of other population groups like young people who are not able to find an adequate job offer next to their home municipality. The interrelations between out-migration of the youth, aging in structurally weak rural areas and the continuous loss of infrastructure become evident.

Although half of the respondents describe themselves as "active" and interested in "the future and fate of their residential municipality", half of them do not articulate their concerns publicly. Furthermore, $39 \%$ of them have already taken part in assemblies and village renewal activities; the latter often is being identified as a relevant opportunity for senior citizens (see amongst others Bednariková 2012).

Blending one's behaviour related to articulation of concerns with one's participation in assemblies or village renewal activities, it can be found, that one third of those, who articulate their concerns publicly, also participate in assemblies or village renewal activities, about $20 \%$ do not articulate their concerns publicly, but take part in assemblies or village renewal activities; and one third neither articulates their concerns publicly, nor participates in municipal development activities.

This indicates high reliance on the municipality as a "system as a local authority to act as a carer".

\section{Anticipating the (future) migration behaviour of today's best ager: high willingness to stay and to age in place}

First of all, among the best agers a high willingness "to age in residence" can be found. For similar results see amongst others Kramer and Pfaffenbach (2011).

However, five relevant motives that possibly can promote out-migration have been identified: illness and need for (long-time) care, death of one's husband/wife, one's own house turns into a burden (for similar results see Wiles et al. 2009), loss of auto-mobility, and lack of infrastructure.

Related to the aspect of illness and need for (long-time) care, the respondents "realistically" estimate the importance of ambulant care and stationary care for the elderly.

\section{Synthesis of results and breaking points in structurally weak rural municipalities}

Heterogeneity among primary dwellers aged 55 to 65 years regarding socio-economic and -demographic aspects, living conditions and spatial lifestyles already is high and is still increasing. Different occupational and migration biographies as well as personal attributes (e. g. financial capacities, socio-spatial patterns of family support) imply a range of experiences and habits, claims and demands, and cause differences relating to the evaluation of one's local quality of life. Collectively, themes that touch old age and frailty are being repressed.

Auto mobility has been widely spread among population aged 55 to 65 years. This implies an increasing external orientation and more regionalised life styles (freedom of choice related to goods and services) that lead to a mismatch of evaluation of the quality of local supply structures and shopping behaviour comprising different infrastructure acceptance from the stakeholders. Best agers wish to be able to drive a car as long as possible and to stay in good health up to old age (for similar findings see Erickson, Call and Brown 2012). These factors are highly relevant for the maintenance of one's subjective quality of life.

There is a high loyalty to location related to leisure behaviour. It also depends on the residences of family members, relatives, and friends. Social cohesion within the families, family support is being weakened by socio-spatial patterns. 
One's own house and garden, as well as the quality of the residential areas and the housing environment ("nature") plays an important role. Related to spatial perception, unpleasant changes within the residential municipalities and deficiencies individually are being balanced with amenities and emotional bonds.

Compared to the number of stressed deficiencies and identified negative developments, there is little affection or rather stated reasonableness.

There is a mismatch of (spatial) perception of deficiencies and uncertainties relating to one's future quality of life, and the willingness to take functions, and political scopes at the municipal level.

Wishes addressed to the rural residential municipalities in essence comprise infrastructural and atmospheric aspects (see Fischer 2009). Best agers are interested in the future of their rural residential municipality, but partly take part in assemblies and village renewal activities. There is a mismatch of retired and self-described "active" persons and persons, who actually volunteer and little interest in taking leadership functions of associations.

There is a high willingness to age in residence, only a small number of best agers think about out-migration. However, concerns related to their future quality of life and their worries about the ability to age in residence refer to the death of the marital partner, to the impossibility of being able to do the works around one's house and garden, and on one's socio-economic situation at old age. Despite high willingness to age in residence, preventive approaches regarding freedom from barriers of one's own house, as well as old-age provision are not common among the best agers.

Structurally weak rural municipalities (already) face collective aging and population decline that trigger the real of unfavourable development and e. g. leads to further financial losses (see Erickson, Call and Brown 2012).

Structural challenges refer to small population, increasing heterogeneity of the best agers, small amount and high fluctuation of actual demanders for infrastructure, and decreasing financial opportunities and imply the challenge of how to continue to provide goods and services at the local level, considering a (future) collective of non-automobile persons at very old age. In Austria, there still is no evidence referring to visible success and sustainability of "simple and economic solutions" in order to maintain basic supply and to guarantee a minimum level of quality related to provision of daily supply of goods.

\section{Conclusions}

Maintaining or rather improving the quality of life for all stakeholders at the so-called "Third Age” means coping with a number of challenges: This phase of life which is being entered at the beginning of the sixth decade of life (Bundesministerium für Arbeit, Soziales und Konsumentenschutz 2008, 202) can be characterised by (financial) independency, increasing individuality of spatial purchasing behaviour and mobility patterns (most of the inhabitants are automobile!), as well as good health. That is why less favoured rural municipalities have limited leeway to alternative solutions for gaining local provision with good reachability on foot.

The organisation of demander-oriented mobility for non-automobile persons will become a crucial challenge for small rural municipalities: Over time, the stakeholders individually have evolved complex everyday routes and trip chains. Carpooling is rare. That is why the best agers themselves as well as political decision-makers worry about the entrance into "postautomobility", which marks a loss of quality of life.

There is a number of approaches to meet the goal that the goods arrive at the customer's door: They comprise door-to-door delivery as well as mobile merchants and online-shopping. From a long-term perspective should be noted the necessity of continuous demand and acceptance of these kinds of provisions as well as the difficult delivery conditions in sparsely populated rural areas. Furthermore, in the opinion of most of today's best agers there is no full-value alternative to traditional shops. 
In contrast, there is a demand for mobile personal services (e. g. hairdressers, pedicure and manicure). In this regard, convenience is essential.

Awareness-raising measures like participation processes that comprise rural population at all ages do not significantly contribute to the maintenance of local daily supply structures, due to the fact that on the one hand most of the participants do not belong to those who already depend on spatial nearness and reachability on foot, and on the other hand the neighbouring communities' tempt with their provision structures (supermarkets).

In addition, over time social networks and village communities break down more and more: Traditional meeting places like shops, pubs and the doctor's practice become less important, because daily life becomes "more private", the circle of friends becomes more selective and the traditional associations do not fit the personal interests any longer.

Although the loss of social cohesion is being perceived collectively, still there is small affection. Those among today's older generation who live alone and do not have reliable social networks on the spot, depend on neighbouring and support that often has to be organised professionally.

Relating to solutions that base on volunteering and mutual support, the real circumstances in everyday rural life as well as specific local constellations comprising strengths and weaknesses have to be considered.

Maintaining quality of life at the so-called "fourth age" to many older people is equal to "aging in place" and is always connected with high costs and personnel deployment. The demand for ambulant (elderly) care is increasing in structurally weak rural areas. Against the background of lacking barrier-freedom of the households both related to best agers and very old people, declining amounts of (potential) care-givers, increasing efforts of maintaining "one's house and garden" and long distance trips of professional home-visit nursing staff due to unfavourable topographic conditions especially in remote alpine rural areas bring to mind the following thought: Stationary care for the elderly probably will become the only option of high-quality provision at "forth age". Against the backdrop of high rootedness, the future relevance of alternative housing forms like "assisted living" is still unclear. Additionally, in case of severe long-time care a further change in residence to a nursery home will be necessary.

Above all, poverty at older age will affect solution-finding and decision-making in structurally weak rural areas and probably will lead to shifts from nationwide uniform standards.

\section{Acknowledgement}

This article bases on the authors' current research project "Old people in rural areas - How to type a changing population group" funded by Emil Boral Foundation, Zurich. Special thanks go to the mayors and to all best agers of the case-study municipalities who actively supported this project.

\section{References}

[1] Bednaříková, Z. (2012). Participation of active seniors in rural areas in public Life. European Countryside (3) 2012: 208-216. Doi: 10.2478/v10091-012-0024-5.

[2] Born, K. M., Goltz, E. \& Saupe, G. (2004). Wanderungsmotive zugewanderter älterer Menschen. Ein anderer Blick auf die Entwicklungsprobleme peripherer Räume in Brandenburg. Raumforschung und Raumordnung 2, 109-120.

[3] Burholt, V. \& Dobbs, Ch. (2012). Research on rural ageing: Where have we got to and where are we going in Europe. Journal of Rural Studies (2012). Doi: 10.1016/j.jrurstud.2012.01.009.

[4] Davies, A. (2011). On constructing ageing rural populations: 'Capturing' the grey nomad. Journal of Rural Studies 27(2), 191-199. Doi: 10.1016/j.jrurstud.2011.01.004. 
[5] Erickson, L. D., Call, V. R. A. \& Brown, R. B. (2012). SOS - Satisfied or Stuck, Why Older Rural Residents Stay Put: Aging in Place or Stuck in Place in Rural Utah. Rural Sociology 77 (3): 408-434. Doi: 10.1111/j.1549-0831.2012.00084.x.

[6] Fischer, T. (2005). Aging in rural areas - A spatial analysis. Doctoral thesis. Vienna: University of Natural Resources and Life Sciences.

[7] Fischer, T. (2009). Lecture series on the future of aging in rural areas. Contribution to future-dialogues "Aging in Burgenland" in the context of rural renewal in BurgaubergNeudauberg, Eberau and Rohr in Burgenland.

[8] Geißler, C. (2003). Für einen Perspektivenwechsel: Die Potenziale des Alters als Triebkräfte gesellschaftlicher Entwicklung. Raumforschung und Raumordnung 5, 395-403.

[9] Glasgow, N. \& Brown, D. L. (2012). Rural Aging in the United States: Trends and contexts. Journal of Rural Studies (2012). Doi: 10.1016/j.jrurstud.2012.01.002.

[10] Hochaltrigkeit in Österreich. Eine Bestandsaufnahme (2008). Wien: Bundesministerium für Arbeit, Soziales und Konsumentenschutz.

[11] Kramer, C. \& Pfaffenbach, C. (2011). Junge Alte als neue "Urbaniten"? Mobilitätstrends der Generation 50plus. Raumforschung und Raumordnung 69, 79-90.

[12] van Dam, F., Heins, S. \& Elbersen, B. S. (2002). Lay discourses of the rural and stated and revealed preferences for rural living. Some evidence of the existence of a rural idyll in the Netherlands. Journal of Rural Studies 18(4), 461-476. Doi: 10.1016/S07430167(02)00035-9.

[13] Walsh, K., O'Shea, E., Scharf, Th., Murray, M. (2012). Ageing in changing community contexts: Cross-border perspectives from rural Ireland and Northern Ireland. Journal of Rural Studies (2012). Doi: 10.1016/j.jrurstud.2012.01.012.

[14] Wiles, J., Allen, R. E. S., Palmer, A. J., Hayman, K. J., Keeling, S. \& Kerse, N. (2009). Older people and their social spaces: A study of well-being and attachment to place in Aotearoa New Zealand. Social Science \& Medicine 68(4). 664-671. Doi: 10.1016/j.socscimed.2008.11.030. 